\title{
The Implementation and the Guarantee Mechanism for Innovation and Entrepreneurship Education
}

\author{
Jianguo Luo ${ }^{1}$ \\ School of Mechanical and Electrical Engineering, North \\ China Institute of Science and Technology, 101601 \\ Beijing, China \\ luojg_1598@126.com
}

\author{
Jieqing Qiu ${ }^{2}$ \\ Graduate School, North China Institute of Science and \\ Technology, 10160 \\ Beijing, China \\ qiujieqinggood@163.com
}

\begin{abstract}
The development of innovative and entrepreneurial education is an effective measure to deepen the reform of higher education and to promote full employment. This paper introduces the ways to realize the innovation and entrepreneurship education from the perspective of theory and practice, and gives some suggestions for the guarantee mechanism of innovation and entrepreneurship education.
\end{abstract}

Keywords-Innovation and entrepreneurship education; Higher education; Implementation; Guarantee mechanism

\section{INTRODUCTION}

University innovation and entrepreneurship education is an important way to cultivate students' innovative consciousness and subjective initiative, adapt to the trend of globalization and promote economic development.

At present, the innovation and entrepreneurship education in Chinese universities is still in its infancy. There are still prominent problems that cannot be ignored, such as unscientific positioning of innovation and entrepreneurship education; single teaching methods, unbalanced teacher resources, and ineffective innovation and entrepreneurship education; and unreasonable curriculum structure., behind the content, innovation and entrepreneurship education from reality and so on. Therefore, research on the ways to achieve innovation and entrepreneurship education and the research on the safeguard mechanism have important practical significance.

\section{THEORETICAL APPROACHES TO INNOVATION AND ENTREPRENEURSHIP EDUCATION}

The basic elements of the talent cultivation model can be summarized as: training objectives, training content, teaching methods, and other aspects. Therefore, the reform of the innovation and entrepreneurial talent training model in colleges and universities needs to focus on the following aspects [1-2].

\section{A. Emphasize innovation and practicality, and clarify the requirements for the cultivation of innovative entrepreneurial talents}

The training goal is to establish the basis for innovation and entrepreneurship education, and is the basis and standard for evaluating the level of innovation and entrepreneurship education. In order to protect the direction and quality of innovation and entrepreneurship education, the goal of innovation and entrepreneurship education must be clear. But the overall concept is the same, that is: to establish a studentoriented education concept, to cultivate complex and applied talents with innovative entrepreneurial spirit and ability, strong sense of social responsibility and noble professional ethics, mastery of professional knowledge, and certain knowledge in economy, management, finance, finance and accounting, and law.

\section{B. Pay attention to the cultivation of innovation ability and improve the curriculum system for the cultivation of innovative and entrepreneurial talents}

The innovation and entrepreneurship education knowledge system in colleges and universities is complex and involves the integration of multiple disciplines. Therefore, the top-level design of the curriculum system must be carried out from the perspective of discipline integration. The talent training program is the most concentrated expression of the school's idea of running schools and educational thoughts. It is a programmatic document for carrying out education and teaching. Therefore, integrating innovation and entrepreneurship education into the talent training program can fundamentally guide the development law of innovation and entrepreneurship education. Greatly promote the continuity and orderliness of innovation and entrepreneurship education.

The key to building a systematic and scientific innovation and entrepreneurship education curriculum system is to integrate the ideas of innovation and entrepreneurship into the existing professional curriculum system in a scientific and effective way. Therefore, at the specific implementation level, according to the characteristics of the existing different disciplines, the general knowledge of innovation and entrepreneurship courses, subject basic courses, and specialized courses should be classified and implemented, and 
the arbitrarily set up of courses should be reduced so as to achieve a seamless connection between innovation and entrepreneurship education and professional education, so that the professional quality and creative thinking of college students can be comprehensively trained and improved.

\section{Innovate educational teaching mode In close connection with practice}

The main body and the ultimate goal of the cultivation of innovative talents is the improvement of students' quality of innovation and entrepreneurship. Not only is it necessary to improve professional knowledge, but more importantly is the improvement of innovation and practical ability. To this end, it is necessary to change the traditional "cramming" indoctrination mode. Consciously reformed the education and teaching model and actively adopted new teaching methods such as discussion, inspiration and practical teaching, which greatly improved the depth and breadth of student participation in the classroom, and effectively promoted innovation and entrepreneurship.

\section{THE WAY TO REALIZE INNOVATION AND ENTREPRENEURSHIP EDUCATION}

\section{A. Face practice and reform the curriculum system}

Innovation and entrepreneurship education is different from traditional knowledge education. Its typical feature is actual combat. Therefore, in the curriculum setting, it is necessary to break the status quo of outdated teaching contents, single teaching methods, and the purpose of teaching to break away from the actual needs of enterprises. For this reason, it is necessary to collaborate with industry enterprises to innovate and jointly formulate a curriculum system with typical application characteristics [3].

\section{B. Renew ideas and innovate teaching mode}

The end result of improving entrepreneurial ability is the practice of students. The current teaching model is mainly based on students' passive listening. Therefore, it is necessary to use innovative thinking to make bold changes to the traditional teaching model. Our school actively uses Internet tools to boldly adopt the "Internet + " teaching model and achieved good teaching results. The specific practices are as follows [4].

1) Reconstruct teaching mode using hybrid teaching method based on MOOC+ flipping classroom: MOOC (massive open online courses) is a large-scale open online course. In recent years, with the continuous popularization of Internet technology, the use of PCs or mobile phones has enabled students to conduct self-learning anytime and anywhere. The learning methods are convenient and flexible, and have a strong initiative. In addition, students can participate in flipping classes while learning on the MOOC platform, which greatly increases the depth of students' participation in classroom teaching, and the teaching effect is significantly improved.
2) Open the WeChat public number service platform: The WeChat public number service platform can not only be used in classroom interactive teaching but also can provide students with various types of entrepreneurial information. The main functions of the integrated service platform include: entrepreneurship knowledge dissemination, entrepreneurship teaching assistance, entrepreneurial activity organization, start-up team connection, and entrepreneurial project management, etc. The information volume is large and timely.

\section{Actively carry out the second class that focuses on practical teaching}

Strengthen the practice teaching of innovation and entrepreneurship education, and actively carry out the second classroom activity that takes social practice and community activities as the main form.

Social practice and community activities can cultivate students' good psychological quality, social communication ability, creative thinking and innovative ability. They can subtly cultivate the students' entrepreneurial quality and ability, thus laying a good foundation for entrepreneurship.

\section{Actively introduce social resources and strengthen practical education}

Entrepreneurship education cannot be confined in a selfcontained manner, and it requires close cooperation with governments, enterprises, venture capital, alumni and other multi-resources to create synergies and complement each other's advantages. It actively builds off-campus practice bases, university science and technology parks, business parks, and entrepreneurial incubator bases. Strengthen the construction and sharing of practical teaching platforms and strive to enhance students' practical ability in innovation and entrepreneurship.

\section{THE GUARANTEE MECHANISM OF INNOVATION AND ENTREPRENEURSHIP EDUCATION}

The smooth development of innovation and entrepreneurship education in colleges and universities needs the attention and support of governments at all levels and all levels of society. In order to better promote the deepening of innovation and entrepreneurship education activities for college students, we must focus on hardware and software to ensure guarantee [5].

\section{A. Hardware guarantee}

1) Establish and improve the leadership institution of innovation and entrepreneurship education organizations: Only by establishing a well-organized, smooth running organization can we ensure the smooth and orderly implementation of innovation and entrepreneurship education activities in colleges and universities. In order to strengthen organizational leadership and resource allocation, colleges and universities must set up an innovation and entrepreneurial leadership group led by school leaders. The members should be composed of relevant functional departments and the heads 
of various secondary departments and supervising experts. The leading group consists of offices for the daily management of the organization and orderly progress. At the same time, an innovation and entrepreneurship education organization should be established in the secondary department responsible for teaching tasks, and be responsible for the organization, implementation, and monitoring of innovation and entrepreneurship teaching.

2) Strengthen the Construction of Innovative Entrepreneurial Teachers.: Qualified teachers are the prerequisite for carrying out innovation and entrepreneurship education. By "going out, please come in" approach to create a "double-qualified" team of innovative entrepreneurship. Firstly, in the school, teachers with a certain degree of innovation and entrepreneurship knowledge and background should be selected as teachers for innovation and entrepreneurship education; Second, training for the innovation and entrepreneurial ability of the teaching team should be increased; Third, to employ outstanding entrepreneurs with certain practical experience and high professional accomplishment and outstanding alumni with outstanding performance as external experts in school innovation and entrepreneurship education to improve the quality of personnel training.

3) Establish and improve the fund guarantee mechanism: Funds are the necessary basic conditions for carrying out innovation and entrepreneurship education. For this reason, colleges and universities should increase investment in innovation and entrepreneurship education funds and use funds rationally and efficiently. At the same time, we should actively expand the financing channels for innovation and entrepreneurship education. For example, Cooperative government, industry enterprises, well-known alumni and other organizations or individuals set up innovative and entrepreneurial education funds.

4) Establishing innovation and entrepreneurship parks and achievements incubation base: Schools should actively create innovation and entrepreneurship parks and results incubator bases to provide a full range of high-level hardware and software facilities for students' innovation and entrepreneurship. At the same time, we can use the scientific research strength of the school, the team of experts, the support of national and local policies to integrate social resources, and provide technical and platform support services for student projects.

\section{B. Software guarantee}

1) Create a scientific and rational innovation and entrepreneurship education curriculum system: Embedding the innovation and entrepreneurship education curriculum in the talent training program design can grasp the development context of innovation and entrepreneurship education for undergraduates from the source. Innovation and entrepreneurship education involves the integration of multiple disciplines and requires the design of a curriculum system from an interdisciplinary perspective. The organic combination of innovation and entrepreneurship education courses and public basic courses, professional basic courses, subject professional courses, and school-wide general education courses makes it possible to infiltrate the ideas and content of entrepreneurship education in the teaching of public courses, subject courses and professional courses.

2) build a digital software platform: With the rapid development of Internet and big data, it has become an inevitable trend to build a digital platform for innovation and entrepreneurship.The digital platform has a variety of forms, including official websites, WeChat platforms, mobile phone APPs, etc. With the development of information technology, contents and forms will be more flexible.The digital platform can realize the integration and sharing of various types of information resources, including curriculum resources, teacher resources, expert resources, corporate resources, project resources, policy resources, laws and regulations, etc., to meet the learning needs of students in the "Internet +" environment. To provide students with timely, efficient and comprehensive guidance and services. The establishment of a digital platform will provide a tremendous impetus to the development of innovation and entrepreneurship education.

\section{CONCLUSION}

Innovation and entrepreneurship education is not only the work of colleges and universities itself, but also a major event for the country, society, and enterprises. It determines the country's long-term stability, social stability, and economic growth. Therefore, it requires universities, countries, societies, and companies to collaborate on innovation., Cooperate with each other to form a multi-party guarantee mechanism so that innovation and entrepreneurship education can continue to be carried out in a healthy and healthy manner.

\section{ACKNOWLEDGMENT}

This work was financially supported by NCIST High Education Research Fundation (HKJYGH201604), and HeBei Province Education Reformation Foundation (2015GJJG254), and HeBei Province Education Association Fundation (GJXHZ2017-06). 


\section{REFERENCES}

[1] Zhao Jianling. Research on the training mode and guarantee mechanism of innovative and entrepreneurial talents in financial institutions of Finance and economics [J]. Journal of Hebei University Of Science and Technology (SOCIAL SCIENCE EDITION), 2017, 17 (2): 101-106. (In Chinese)

[2] Zhang Qiang. The theory of innovation and entrepreneurship education in Colleges and Universities: connotation, mechanism and path [J]. Social Sciences, 2017, 32 (4): 160-163. (In Chinese)

[3] He Xingwang. An analysis of the path of College Students' entrepreneurial ability promotion based on "creating guests" under the background of "creation" [J/OL]. Journal of Anhui Business College of Vocational Technology (SOCIAL SCIENCE EDITION):1-3. (2017-0904). Http://kns.cnki.net/kcms/detail/34.1242.Z.20170904.1530.004.html. (In Chinese)

[4] Education: improving students' ability to practice and innovate -[DB/OL]. 2017-09-04. http://news.ncist.edu.cn/article/2016-1215/art16126.html of entrepreneurship education in North China Institute of Science and Technology.

[5] Li Shijiao. The construction of College Students' innovation and entrepreneurship education system $[\mathrm{J}]$. Heilongjiang higher education research, 2011, (9): 119-12. (In Chinese) 